\title{
On the Pharmacology of Bromelain: An Update with Special Regard to Animal Studies on Dose-Dependent Effects
}

\author{
Hermine Lotz-Winter \\ Rheinstraße 15, D-6082 Mörfelden-Walldorf, Federal Republic of Germany \\ Received: November 27, 1988; Revised received: October 2, 1989
}

\begin{abstract}
Bromelain, a standardized complex of proteases from the pineapple plant, is absorbed unchanged from the intestine of animals at a rate of $40 \%$; in animal experiments it was found to have primarily anti-edema, antiinflammatory, and coagulation-inhibiting effects. These effects are due to an enhancement of the serum fibrinolytic activity and inhibition of the fibrinogen synthesis, as well as a direct degradation of fibrin and fibrinogen. Bromelain lowers kininogen and bradykinin serum and tissue levels and has an influence on prostaglandin synthesis, thus acting antiinflammatory. In in vitro and in animal studies, experimentally induced tumours could be inhibited by bromelain. Although many studies do not give extensive statistical data, the effects of bromelain in animal studies seem to be dose-dependent. Further investigations have to be carried out.
\end{abstract}

\section{Key words}

Bromelain, Ananas comosus, animal experiments, pharmacology.

\section{Introduction}

The bromelains, a group of closely related proteolytic enzymes are obtained from the stem of the pineapple plant (Ananas comosus). Pineapple juice has been used for a very long time as a folk medicine by the natives of the tropics against quinsy, as a digestive aid, and used externally - against horny epidermis. The presence of proteolytic enzymes in pineapple juice was demonstrated already in 1891, the active substance was isolated and studied by several groups of investigators.

Today, bromelain is used for the treatment of cases of inflammation associated with edema (e.g. caused by traumatic injuries, post-operative edema), of inflammations of the respiratory tract, of inflammations caused by circulation disturbance (such as thrombophlebitides, venous ulcers), and to enhance the activity of antibiotics.
The purpose of the present review is to give a survey of the pharmacology of bromelain and to highlight some relevant animal studies regarding the dose-dependency of pharmacological effects.

\section{Chemical Structure of Bromelain}

Bromelain consists of at least 5 very closely related proteolytic enzymes (1). They differ somewhat from each other in substrate specifity and in the optimum $\mathrm{pH}$ for enzymatic activity. As the single enzymes are closely related, it seems sensible to treat them as a single entity. The international classification of enzymes, too, discusses bromelain like a single enzyme.

As known since 1940, the optimum $\mathrm{pH}$ for proteolytic activity of bromelain is about $\mathrm{pH} 7$. Substrates susceptible to bromelain include many common protein materials, such as casein, gelatin, collagen, globulins, and muscle fiber.

The proteolytic activity of bromelain can be determined by various different methods. Today it is common to use FIP units or GDU units.

\section{On the Pharmacodynamic Properties of Bromelain}

\section{Results of animal studies}

In animal studies, bromelain showed a multitude of effects (see Table 1), the most important ones will be discussed subsequently.

\section{Effects on experimentally produced edema and inflammations}

There is very much evidence concerning the prevention and/or inhibition of experimentally induced footpad edema by bromelain. Bromelain reduced footpad edema caused by egg-white, carrageenin alone, and potentiated by forskolin and ACE-inhibitors, dextran, bradykinin, and yeast (for a review see 2, 3, 4).

Uhlig and Seifert (1981) investigated the anti-edema activity of bromelain in traumatic edema of rats. Bromelain was administered enterally in doses of 
Table 1 The most important effects of bromelain observed in animal experiments.

* Antiedematous effects on experimentally induced rat paw edema $(2,3,4,5$, 6)

* Reduction of capillary permeability caused by tissue kininogens $(4,24)$

* Reduction of absorption time of haematoma (see 2)

* Inhibition of lung edema, caused by i.v. epinephrin injection (7)

* Protection against bronchial edema caused by irritating agents (see 2)

* Degradation of bradykinin $(4,7)$

* Effect on prostaglandin synthesis (25)

* Decrease of exudate volume in experimentally induced pleurisy (8)

* Effect on biood coagulation:

Increase of prothrombin time $(13,14)$

increase of antithrombin levels $(13,14)$

Platelet aggregation inhibitory effect (14)

Increase of plasmin levels (13)

* increase of antibiotic levels in body fluids $(9,10,11)$

* Increase of pentobarbital-induced sleeping time (see 2)

* Decrease of precancerous lesions $(15,16,17)$

$80 \mathrm{mg}$ per kg body weight by duodenal probe. Compared to a control group treated with saline solution, the maximal volume of the edema was significantly reduced and the regression of edema was accelerated very much (reduction of $50 \%$ after 12 hours, in the control group after 20 hours). A third group of animals received $32 \mathrm{mg}$ bromelain by intraperitoneal injection. An anti-edema activity could be seen only in the first 6 hours of investigation. The lower efficacy of bromelain after i.p. administration could be explained, according to the authors, with the lower dose of bromelain, which had been chosen originally to provide the same effectivity. A complete explanation was not given (5).

A study by Pirotta and De Giuli-Morghen showed a dose-dependent anti-edema activity in carrageenin-induced footpad-edema of the rat (2). One hour before carrageenin injection, the animals were treated with saline or respectively $25,50,100 \mathrm{mg} / \mathrm{kg}$ bromelain by oesophageal tube. After bromelain treatment, while it increased in the time until the 5th hour, the edema was significantly reduced at every observation time. In the limits of the dose of administered bromelain, e.g. between 25 and $100 \mathrm{mg} / \mathrm{kg}$, the edema-inhibiting response to the dose (after $1.5,3$, and 5 hours) did not deviate from a straight line because the non-linear components of the regression were not significant. Therefore, the antiphlogistic response was proportional to the log of the dose of administered bromelain. At the 7th hour, the non-linear components of the regression were significant. The lowest dose $(25 \mathrm{mg} / \mathrm{kg})$ already had a significant effect on the anti-edema activity ( $p$ $<0.05$ ). The activity was highest with the $100 \mathrm{mg}$ dosage (see Table 2). Statistical significance of the effects within the dose ranges has not been calculated.

Table 2 Reduction of carrageenin paw edema in comparison to an untreated control group with different bromelain doses; The antiphlogistic response was proportional to the dose log. Statistical calculations within the dose range are not shown (2).

\begin{tabular}{l|l|l|l|l}
\hline $\begin{array}{l}\text { Bromelain } \\
\text { dose } \mathrm{mg} / \mathrm{kg}\end{array}$ & \multicolumn{5}{l}{$\begin{array}{l}\text { Reduction of edema (\% compared to control } \\
\text { group) after carrageenin injection }\end{array}$} \\
& $\begin{array}{l}1.5 \mathrm{~h} \\
\end{array}$ & $3 \mathrm{~h}$ & $5 \mathrm{~h}$ & $7 \mathrm{~h}$ \\
\hline 25 & -35 & -34 & -46 & -62 \\
50 & -50 & -46 & -55 & -67 \\
100 & -59 & -65 & -73 & -90 \\
\hline
\end{tabular}

In rats with experimentally induced carrageenin- or forskolin-potentiated carrageenin-edema, the intravenous administration of bromelain $(10 \mathrm{mg} / \mathrm{kg}$ weight $)$ led to a significant reduction of edema size. The increase in the footpad volume amounted to $28 \%$ (carrageenin group) or $17 \%$ (forskolin-carrageenin group), respectively, of the increase in a control group not treated with bromelain $(p<$ 0.01 in both groups). The same study was also carried out with a bromelain dosage of $3 \mathrm{mg} / \mathrm{kg}$. The increase of footpad volume was $81 \%$ (not significant) or $59 \%(p<0.01)$, respectively, of the comparable volumes in the control group. Obviously there is a dose-dependent effect (3).

Indications of this dose-dependency are given already in very early studies (update, see 6). In paw edema induced by egg-white, bromelain doses from 1 to $8 \mathrm{mg} / \mathrm{kg}$ weight inhibited the edema from 13 to $60 \%$.

Bromelain also inhibits other experimentally induced types of edema, e.g. adrenaline-induced pulmonary edema (7). In carrageenin-induced rat pleurisy, intravenous bromelain $(10 \mathrm{mg} / \mathrm{kg}$ weight $)$ administration reduced the volume of the pleural exudate in a statistically significant manner. In combination with indomethacin, this effect was even stronger (8).

\section{Increase in tissue and body fluid levels of antibiotics}

There are many reports on the increase of antibiotic levels in tissues and body fluids when proteases such as bromelain are administered concomitantly with antibiotics.

A study with rabbits showed that the penicillin-content of the cerebrospinal fluid, which normally is much lower than in serum, is increased by i.m. and intraduodenal bromelain administration. Doses of 20$25 \mathrm{mg} / \mathrm{kg}$ were used (9).

Rats were treated orally with $100 \mathrm{mg}$ bromelain $/ \mathrm{kg}$ body weight. Subsequently they received $200 \mathrm{mg}$ Cefazolin $/ \mathrm{kg}$ weight. The concentration of Cefazolin in bronchial wash was increased significantly $(61 \%$ after $30 \mathrm{~min}, 79 \%$ after $60 \mathrm{~min}$ as compared to a control group, $\mathrm{p}$ $<0.05$ or $p<0.01$, respectively) (10).

In rabbits, the administration of bromelain increased the blood and urine levels of Ethambutol (11).

The results of animal studies have been confirmed in man. In a placebo-controlled, double-blind study, cantharides solution was applied to the forearm of healthy volunteers, producing blisters. Concomitantly, tetracyclin and bromelain or placebo were given in oral form. The concentration of tetracyclin in the blister fluid was higher in the bromelain group, although the differences to the control group were not statistically significant (12).

Influence of bromelain on blood coagulation

According to in vitro studies and animal experiments, bromelain has an effect on several components of the blood coagulation system. 


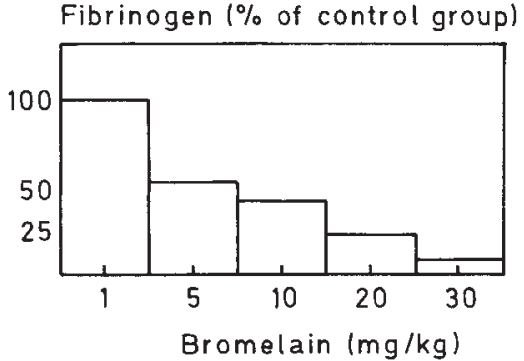

It has been known for a considerable time that bromelain lengthens prothrombin time. Bromelain was administered to rabbits in an oral form at different dosage regimens. The prothrombin and the antithrombin time and serum plasmin concentrations were measured. The minimum effective dosage, which changed the three parameters, was $5 \mathrm{mg} / \mathrm{kg}$. The prothrombin time was increased from 80 to $250 \%$, the antithrombin time showed a parallel increase. Serum plasmin levels were also elevated. The values remain elevated for two or three hours. The study does not give data on the statistical signifance of the results (13).

When bromelain was injected to normal rats, prothrombin time, prothrombin levels, Factor $\mathrm{X}$ (Stuart-Factor), and fibrinogen levels in plasma were lowered in comparison to an untreated control group (14). Bromelain doses of $1,5,10,20$, and $30 \mathrm{mg} / \mathrm{kg}$ weight were administered intravenously. The change of the tested parameters was dose-dependent, although no data on statistical significance are given (Fig. 1). In none of the samples were fibrinogen degradation products with a low relative molecular mass found at a concentration higher than $8 \mu \mathrm{g} / \mathrm{ml}$. In the same study, ADP-induced platelet aggregation after administration of $30 \mathrm{mg}$ bromelain was tested: in all treated animals, but in no controls, aggregation was partially or totally reversible within 5 minutes.

The serum fibrinolytic activity (SFA) was increased, too, when bromelain was administered enterally to rats (2). In the limits of the dose of administered bromelain, i.e. between 25 and $100 \mathrm{mg} / \mathrm{kg}$, SFA-increasing response to the dose (observed after 1.5, 3, and 5 hours) was proportional to the log of the dose of administered bromelain, whereas SFA remained unchanged after placebo treatment (Table 3). The increase of SFA at every observation time was statistically significant.

\section{Interference with growth of malignant cells}

As bromelain inhibits platelet aggregation, in vitro and in vivo studies were carried out to investigate a possible inhibition of tumour growth and antimetastatic activity.

In vitro, bromelain inhibited the growth of Lewis lung carcinoma, YC-8 lymphoma, and MCA-1 ascitic tumour cells (15). In experimentally induced skin cancer in hairless mice, bromelain feeding enhanced the resistance of mice to UV irradiation. The bromelain group took longer to develop precancerous lesions $(16,17)$. An in vivo Lewis
Table 3 Increase of serum fibrinolytic activity of bromelain treated animals in comparison to an untreated control group with different doses of bromelain (2). The increase at every observation time was statistically significant.

\begin{tabular}{|c|c|c|c|c|}
\hline \multirow[t]{2}{*}{$\begin{array}{l}\text { Bromelain } \\
\text { dose } \mathrm{mg} / \mathrm{kg}\end{array}$} & \multicolumn{4}{|c|}{$\begin{array}{l}\text { Increase in serum fibrinolytic activity } \\
(\%) \text { compared to a control group at time } X \\
\text { after bromelain administration }\end{array}$} \\
\hline & $2.5 \mathrm{~h}$ & $4 \mathrm{~h}$ & $6 \mathrm{~h}$ & $8 \mathrm{~h}$ \\
\hline $\begin{array}{r}25 \\
50 \\
100\end{array}$ & $\begin{array}{l}+21 \\
+36 \\
+55\end{array}$ & $\begin{array}{l}+116 \\
+156 \\
+179\end{array}$ & $\begin{array}{l}+66 \\
+84 \\
+134\end{array}$ & $\begin{array}{l}+63 \\
+68 \\
+126\end{array}$ \\
\hline
\end{tabular}

lung carcinoma study in mice showed a reduction of lung metastases in bromelain-treated animals $(140 \mathrm{mg}$ or $400 \mathrm{mg} / \mathrm{kg} /$ day). The numbers of pulmonary metastases were reduced in a dose-dependent manner (18).

Whereas bromelain's antineoplastic effects were up to now explained primarily by its fibrinolytic and platelet aggregation inhibitory activity and a possible lysing effect on tumour antigen-antibody complexes, which prevent the attack of cytotoxic $\mathrm{T}$ lymphocytes, a recent in vitro study by Maurer et al. (19) offers a possible independent explanation for the observed cytostatic potential of bromelain. It was shown that bromelain, in vitro, induces leukemic cells to differentiate and thus prevents tumour growth. The effect was shown in three different leukemic cell lines (one myeloid mouse leukemia, and two human leukemia forms). In two of the experiments the differentiation increased with the administered bromelain dose, in one of the experiments a bell-shaped curve was obtained, which could not be explained satisfactorily.

Dose-dependent effects in animal experiments and dosage regimen in clinical studies

Although some of the performed animal experiments do not give statistical parameters, the effects of bromelain in animals seem to be dose-dependent. The least effective dosage is probably $5 \mathrm{mg} / \mathrm{kg}$ weight (13). This would correspond to a human dose of $350 \mathrm{mg}$ daily in clinical studies. Besides, a dose-dependency was seen in clinical studies, too, especially in serious cases, where the administration of doses up to 8 times the normal dose showed beneficial effects (20). Nevertheless, it is problematic to transfer the results of animal studies to man. In human medicine, dosage schemes of up to $1000 \mathrm{mg}$ bromelain per day are recommended, which corresponds to a dose of $15 \mathrm{mg} / \mathrm{kg}$ weight (21). 


\section{Toxicity of Bromelain}

Results of experiments on acute toxicity are listed in Table 4 (22). Chronic toxicity was tested in rats receiving a chow with a content of up to $1 \%$ bromelain over 3 months. There was no significant difference between a control group and the bromelain group regarding weight, haematology, and blood chemistry. No damage to paws and snouts could be observed, nor pathological changes in vital organs.

Table 4 Acute toxicity of bromelain in different animal species. $L_{50}$ could not be determined during oral administration (18).

\begin{tabular}{lcc}
\hline $\begin{array}{l}\text { Animal } \\
\text { species }\end{array}$ & \multicolumn{1}{c}{$\mathrm{LD}_{50}$} & Mode of application \\
\hline mice & $30-35 \mathrm{mg} / \mathrm{kg}$ & i.v. \\
rabbits & $20 \mathrm{mg} / \mathrm{kg}$ & i.v. \\
mice & $36.7 \mathrm{mg} / \mathrm{kg}$ & i.p. \\
rats & $85.2 \mathrm{mg} / \mathrm{kg}$ & i.p. \\
mice & $>10 \mathrm{~g} / \mathrm{kg}$ & oral \\
rats & $>10 \mathrm{~g} / \mathrm{kg}$ & oral \\
\hline
\end{tabular}

When injected rapidly, bromelain caused a blood pressure drop of $30-40 \mathrm{~mm} \mathrm{Hg}$ and an increase of heart rate to $22-26$ beats per minute in anesthetized dogs. Within 10 minutes values returned to normal, they did not change when the injection was carried out more slowly (22).

\section{Mechanism of Action Responsible for the Anti-Edema and Anti- inflammatory Effect}

Bromelain's mechanism of action is not yet completely known. The following pharmacological principles are discussed as being the main causes of the effects, which were observed in the reviewed animal studies:

1. direct effect on the fibrinogen-fibrin system;

2. indirect effects on blood coagulation;

3. inactivation of bradykinin in inflamed tissues; and

4. effect on prostaglandin synthesis.

\section{Fibrinolytic effect}

During inflammation, proteins and fluid exude into the intravascular space through the blood vessel walls. Partial denaturation of these proteins could be responsible for the exudate's increased viscosity. Additionally, plasma fibrinogen is partially degraded in a slightly polymerized form. Thereby the vessels' pores are clogged, even the lumen may be blocked, thus creating a condition of stasis in which the edema fluid is prevented from reentering the vessels.

Bromelain's action is two-fold. Firstly, the fibrin levels are lowered by decreasing the fibrinogen levels (14). Serum fibrinolytic activity is increased (2). The resulting degradation products have a low relative molecular mass and do not decrease the permeability of the blood vessels. Fibrinogen formation is decreased by effects on the prothrombin complex. This is shown in the lengthening of prothrombin time and increased antithrombin levels $(2,13$, 14).
Secondly, depolymerization of fibrin and, possibly, of other proteins is enhanced. Probably, bromelain exerts this effect indirectly by increasing plasmin levels (13). A direct proteolytic effect of bromealin on fibrin is discussed, too. In vitro experiments have shown that bromelain has a very high affinity to fibrin. It depolymerized fibrin seven times faster than fibrinogen (23).

By these mechanisms blood vessel permeability is increased and edema fluid can reenter the vessels, thus resolving stasis (6). Another proof for the increase of vascular permeability by bromelain is the fact that levels of antibiotics in fluids and tissues were increased when applied concomitantly with bromelain $(9,10,11)$. Other proteases had similar increasing effects on permeability: intracutaneous dye spread was increased when animals were pretreated with proteases [see (2)]. Prolonged sleeping time of animals treated with pentobarbital and bromelain concomitantly is due to the same reasons.

\section{Antiinflammatory action}

Plasma and tissue kininogens play an important role in the development of inflammations. They release mediators such as bradykinin, which enhance the inflammatory process. Bromelain lowers kininogen levels and bradykinin levels, respectively, in serum by up to $60 \%$ $(4,7,24)$. In the same studies, the symptoms of inflammation, too, were prevented or decreased. Effects of bromelain on prostaglandin synthesis are discussed. Experiments with rats showed a dose-dependent decrease of prostaglandin $\mathrm{E}_{2}$ levels and thromboxane $\mathrm{B}_{2}$ levels in experimentally induced inflammations (25). In this study, too, there was a decrease of the volume of exudate and of other inflammatory reactions.

\section{Remarks on the Absorption of Bromelain}

As the intravenous and the intraperitoneal administrations of bromelain in animal studies had several adverse effects and favoured the sensibilization against bromelain, it has been administered orally since a long time. Although pharmacological and clinical efficacy could be shown, it was discussed controversely whether or not bromelain was absorbed from the intestine in an unchanged form. Theoretically bromelain, as a protein, could be digested enzymatically in the intestine. On the other hand, the absorption of bromelain could be enhanced by the high degree of glycosylation, which prevents also proteolytic degradation of bromelain in the intestine.

By the use of radioactive tagging (e.g. 26) or by dye-labelling, the absorption of bromelain through the mucosa of the intestine into the blood could be shown. A study with adult rats showed that the high molecular form of radioactively-tagged bromelain was absorbed up to $40 \%$ after intraduodenal administration. With the help of radiochromatography, the radioactivity of high molecular protein and of protein degradation products could be distinguished. Bromelain in serum and lymphatic fluid was identified with rabbit antibromelin serum using an agar diffusion method (27). 


\section{References}

${ }^{1}$ Murachi, T., Neurath, H. (1960) J. Biol. Chem. 235, 99.

2 Pirotta, F., De Giuli-Morghen, C. (1978) Drugs Exptl. Clin. Res. 4, 1.

3 Sugio, K., Daly, J. W. (1983) Life Sciences, 33, 65.

${ }^{4}$ Suda, H., Yamauchi, H., Iso, T. (1984) J. Pharm. Dyn. 7, 372.

${ }^{5}$ Uhlig, G., Seifert, J. (1981) Fortschritte der Medizin 15, 554.

${ }^{6}$ Martin, G., Ehrenreich, J., Asbell, N. (1962) Exp. Med. Surg. 20, 227.

7 Shigei, T., Sakuma, A., Enomoto, T., Oh-Ishi, S., Hatano, R. (1967) Jap. J. Pharmacol. 18

${ }^{8}$ Katori, M., Ikeda, K., Harada, Y., Uchida, Y., Tanaka, K., Oh-ishi, S. (1978) Agents and Actions 8, 108.

9 Giller, F. B. (1962) Am. Jour. Pharm. 124.

10 Kida, J., Kano, K. (1976) Chemotherapy 24, 1619.

11 Sekule, G., Querzola, F., Mini, A. (1969) Boll. Chim. Farm. 108, 119

12 Bodi, T. (1965) Exp. Med. Surg. Supplement, 51.

${ }^{13}$ Smyth, R. D., Brennan, R., Martin, G. J. (1962) Arch. Int. Pharmacodyn. $1,230$.

14 Livio, M., Bertoni, M. P., De Gaetano, G., Donati, M. B. (1978) Drugs Exptl. Clin. Res. 4, 49

15 Taussig, S. J., Szerkeczes, J., Batkin, S. (1985) Planta Med. 51, 538.
${ }^{16}$ Goldstein, N., Taussig, S. J., Gallup, J. D., Koto, V. (1975) Hawaii Medical Journal 34, 3.

17 Taussig, S. J., Goldstein, N. (1976) Krebsgeschehen 8, 4.

18 Batkin, S., Taussig, S., Szekerczes, J. (1988) Cancer Investigation 6 , 241.

19 Maurer, H. R., Hozumi, M., Honma, Y., Okabe-Kado, J. (1988) Planta Med. 54, 377

20 Gutfreund, A. E., Taussig, S. J., Morris, A. D.(1978) Hawaii Medical Journal 37, 143.

21 Nieper, H. A. (1976) Krebsgeschehen 1, 9.

22 Moss, J. N., Frazier, C. V., Martin, G. J. (1963) Arch. Int. Pharmacodyn. 145,1 .

23 Didisheim, P., Lewis, J. H. (1956) Proc. Soc. Exp. Biol, Med. 93, 10.

24 Di Rosa, M., Giroud, J. P., Willoughby, D. A. (1971) J. Pathol. 104, 15.

25 Vellini, M., Desideri, D., Milanese, A., Orini, C., Daffonchio, L., Hernandez, A., Brunelli, G. (1986) Arzneim.-Forsch. 36, 110.

${ }^{26}$ Smyth, R. D., Brenan, R. M., Martin, G. J. (1961) Amer. Jour. Pharm $133,294$.

${ }^{27}$ Seifert, J., Ganser, R., Brendel, W. (1979) Zeitschrift f. Gastroenterologie 17,1 . 